\title{
Yüksek Yoğunluklu Polietilen (YYPE) Esaslı Polimer Kompozitlerin Mekanik Özellikleri Üzerine Nişasta Oranının Etkisi
}

\author{
"Kadir KARAKUŞ", Fatih MENGELOĞLU",2 \\ ${ }^{1}$ Kahramanmaraş Sütçü İmam Üniversitesi, Orman Fakültesi, Orman End.Müh. Böl. Kahramanmaraş \\ ${ }^{2}$ Kahramanmaraş Sütçü İmam Üniversitesi, Fen Bilimleri, Malzeme Mühendisliği Böl.Kahramanmaraş \\ *Sorumlu Yazar: karakus@ksu.edu.tr
}

Geliş Tarihi: 18.03.2016

\section{Özet}

$\mathrm{Bu}$ çalışmada, polimer olarak yüksek yoğunluklu polietilen (YYPE), organik dolgu maddesi olarak mısır nişastası ve uyum sağlayıcı kimyasal olarak maleik anhidritle muamele edilmiş polietilen (MAPE) kullanılmıştır. Polimer kompozitlerin üretimi 88 ton kapasiteye sahip enjeksiyon kalıplama makinesi kullanılarak gerçekleştirilmiştir. Üretilen polimer kompozitlerin fiziksel özelikleri (yoğunluklar) ve mekanik özellikleri (çekme, eğilme ve darbe direnci) tespit edilmiştir. Elde edilen sonuçlara göre YYPE içerisine nişastanın eklenmesiyle çekme, kopmada uzama ve darbe direnci değerlerinin azaldığı ancak yoğunluk, eğilme direnci ve elastikiyet modülü değerlerinin arttığı belirlenmiştir. Ayrıca MAPE kullanımının polimer kompozitlerin mekanik özellikler üzerine olumlu bir etki yaptığı tespit edilmiştir.

Anahtar Kelimeler: Yüksek yoğunklu polietilen (YYPE), Mısır nişastası, Polimer kompozit, Mekanik özellikler

\section{The Effect of Starch Loading on Mechanical Properties of High Density Polyethylene (HDPE) Based Polymer Composites}

\begin{abstract}
In this study, polymer composites were produced utilizing high density polyethylene (HDPE) as a polymer and corn starch flour as organic filler and maleic anhydrite grafted polyethylene (MAPE) as coupling agent. Polymer composites were manufactured using 88 tones pressure capacity injection molding machine. Specific gravity and mechanical properties (tensile, flexural and impact) of the manufactured polymer composites were determined. Results indicated that tensile strength, elongation at break and impact strength decreased with increasing starch loading however specific gravity, flexural strength and both modulus were increased with starch loading. Also adding the MAPE improved the mechanical properties of the polymer composites.

Keywords: High density polyethylene, Corn starch, Polymer composite, Mechanical properties.

\section{Giriş}

Polimer kompozitler iki ya da daha fazla materyalin herhangi bir form ya da kullanımdaki kombinasyonlarıdır. Kompozitler çoğu zaman kendilerini oluşturan materyallerin faydalı özelliklerini alırlar ve bunlardan daha faydalı özelliklere sahip yeni malzemeler meydana getirirler. $\mathrm{Bu}$ özellikler arasında polimer malzemeye kıyasla maliyetinin düşük olması, çevre dostu olmaları, boyutsal stabilitesinin iyi olması, istenilen boyut ve şekillerde üretilebilmeleri, mantarlara ve böceklere karşı daha dayanıklı olmaları; geri dönüşümlü malzemelerden üretilebilmeleri sayllabilir (Karakuş, 2008; Donmez Çavdar ve ark., 2015;

Kaymakc1, 2015; Aydemir, 2015). Polimer kompozit sanayinde malzemenin direnç özelliklerini arttırmak ya da maliyetini azaltmak amacıyla çeşitli dolgu maddeleri kullanılmaktadır (Donmez Çavdar ve ark., 201; Tufan ve ark., 2015). Bu amaçla en fazla kullanılan maddeler başlangiçta mika, kil, kalsiyum karbonat ve cam elyafı gibi inorganik maddeler olmuştur. Ancak bu malzemelerin sert yüzeylere sahip olmalarının üretim makinelerinde sebep olduğu aşınmalar ve maliyetlerinin yüksek olması dolayısıyla alternatif malzemelerin aranmasına gidilmiştir. $\mathrm{Bu}$ organik dolgu maddeleri yenilenebilir, ucuz, düşük yoğunlukta ve islenmesi kolay olması dolayısıyla kısa sürede termoplastik endüstrisinde kabul
\end{abstract}


görmüştür (Karakuş, 2012).

Organik dolgu maddelerinden nişasta kimyasal olarak $\alpha$-D-1-4 glikozid bağlar aracilı̆̆1 ile bağlanmış anhidroglikoz ünitelerinden oluşan bir polimerik karbonhidrattır. Nişasta genellikle doğrusal amiloz ve dallanmış amilopektin gibi iki mikro yapı içeren heterojen materyalden oluşmaktadır. Fiziksel olarak nişasta yaklaşık olarak \%20-45 kristalin özelliğe sahip yarı kristal bir malzemedir. Kristal bölgeler $5 \mathrm{~nm}$ uzunluğunda çift helezonik şeklinde gösterilmektedir. Amilopektinin moleküler ağırlığı amilozdan 100 kat daha fazladır. Amiloz ve amilopektinin oranı nişastanın kaynağına bağlıdır. Nişasta granülleri küçük miktarlarda yağ ve proteinler de içermektedir (Karakuş, 2012; Lu ve ark., 2009; Oakley, 2010). Nişasta ilk olarak poliolefinler (PP ve PE) için dolgu maddesi olarak kullanılmıştır. Daha sonraki yıllarda nişastanın benzer amaçla poliolefinler içerisinde kullanıldığı birçok çalışma yapılmıştır (Raj ve ark., 2001; Franco ve ark., 2004; Gupta ve ark., 2008; Muthukumar ve ark., 2010). Polimer kompozitlerin üretilmesinde yüksek veya düşük yoğunluklu polietilen (PE), polipropilen (PP), polistiren (PS), polivinil klorür (PVC) vb. termoplastik materyaller kullanılmaktadır. Yüksek yoğunluklu polietilen (YYPE) petrolden elde edilen bir malzemedir. YYPE nispeten düz bir zincir yapıya sahip, yoğunluğu $0.94-0.96$ $\mathrm{gr} / \mathrm{ml}$ 'dir. Yarı saydam veya renklidir. En çok kullanılan plastiklerden biridir. Bunlar çoğunlukla boru üretiminde kullanılan malzeme olup, atık su ve basınçlı borularda, şişe, bidon, varil, süt, su, meyve suları, sıvı deterjanlar, oyuncak, elektrik ve elektronik eşya imalatında kullanılmaktadır
(Karakuş, 2008). Bununla beraber YYPE gibi plastiklerin hidrofob özelliği olması ve organik dolgu maddelerinin suyu seven (hidrofilik) bir yapıya sahip olmalarından dolayı polimer kompozitlerin üretilmesinde bu materyaller arasında zayıf bir bağlanma meydana gelmektedir. $\mathrm{Bu}$ nedenle plastik ve dolgu maddesi arasındaki yüzeyler arası bağlanmasını iyileştirmek için ve yapışmayı kuvvetlendirmek için birçok uyumsuzluk giderici kimyasallar kullanılmaktadır. Günümüzde en yaygın olarak kullanılan uyum sağlayicılardan birinin de maleik anhidrit olduğu görülmektedir (Mengeloğlu ve Karakuş, 2008). $\mathrm{Bu}$ çalışmanın amacı enjeksiyon kalıplama yöntemi kullanılarak üretilen YYPE esasli polimer kompozitlerinin mekanik özellikleri üzerine nişasta oranının etkisinin belirlenmesidir. Bununla beraber uyum sağlayıcı kimyasal olan maleik anhidritle muamele edilmiş polietilen (MAPE)'in polimer kompozitlerin mekanik özellikleri üzerine etkisi de araştırılmıştır.

\section{Materyal ve Yöntem Materyal}

$\mathrm{Bu}$ çalışmada polimer malzeme olarak yüksek yoğunluklu polietilen (YYPE), dolgu maddesi olarak mısır nişastası kullanılmıştır. Polimer matrisi olarak kullanilan YYPE $\left(\mathrm{Tm}=134{ }^{\circ} \mathrm{C}\right.$, yoğunluk $=0.96 \mathrm{~g} / \mathrm{cm}^{3}, \mathrm{MFI} / 230^{\circ} \mathrm{C} / 2.16 \mathrm{~kg}=0,36$ $\mathrm{g} / 10 \mathrm{dk})$ Petkim Petrokimya A.Ş. den satın alma yoluyla temin edilmiştir. Misır nişastası ise İstanbul'da faaliyet gösteren Pendik Nişasta fabrikasından satın alma yoluyla temin edilmiştir. Uyumsuzluk giderici olarak Clariant firmasından alınan Licocene PE MA ticari adlı MAPE kullanılmıştır.

Tablo 1: Uyumsuzluk giderici kimyasalın özellikleri

\begin{tabular}{lc}
\hline Özellik & Maleik anhidritle muamele edilmiş polietilen (MAPE) \\
\hline Görünüş & Beyaz toz \\
\hline Yumuşama Noktası & $123^{\circ} \mathrm{C}$ \\
\hline Asit Değeri & $43 \mathrm{mg} \mathrm{KOH} / \mathrm{g}$ \\
\hline $23^{\circ} \mathrm{C}$ 'de Yoğunluk & $0,99 \mathrm{~g} / \mathrm{cm}^{3}$ \\
\hline $140^{\circ} \mathrm{C}$ 'de Viskozite & $300 \mathrm{mPa} . \mathrm{s}$ \\
\hline
\end{tabular}




\section{Polimer kompozitlerin Enjeksiyon Kalıplama Yöntemiyle Üretimi \\ Polimer kompozitlerin üretiminde kullanılan YYPE, dolgu maddesi olarak nişasta ve maleik}

anhidritle muamele edilmiş polietilen (MAPE) oranları belirtilmiştir ve üretim reçetesi Tablo 2' de gösterilmiştir.

Tablo 2: Polimer kompozit üretim reçetesi

\begin{tabular}{cccc}
\hline Kod & $\begin{array}{c}\text { YYPE } \\
(\boldsymbol{\%})\end{array}$ & $\begin{array}{c}\text { Nişasta } \\
(\boldsymbol{\%})\end{array}$ & $\begin{array}{c}\text { MAPE } \\
(\boldsymbol{\%})\end{array}$ \\
\hline H0 & 100 & 0 & 0 \\
\hline H1 & 90 & 10 & 0 \\
\hline H3 & 87 & 10 & 3 \\
\hline H4 & 80 & 20 & 0 \\
\hline H6 & 77 & 20 & 0 \\
\hline H7 & 70 & 30 & 3 \\
\hline H8 & 67 & 30 & 0 \\
\hline \\
\hline
\end{tabular}

reçetelerine bağlı kalınarak, kurutulmuş dolgu maddesi, YYPE ve MAPE yüksek devirli karıştırıcı yardımıyla homojen hale getirilmiştir. Elde edilen homojen karışım daha sonra tek vidalı ekstruder içerisine besleme ağzından verilmiştir. Ekstruder içerisindeki vidanın dönme hızı dakikada 40 devir olacak şekilde ayarlanmıştır. Beş farklı ısıtma alanına sahip olan ekstruder içerisindeki sıcaklıklar 170-180185-190-200 ${ }^{\circ} \mathrm{C}$ olacak şekilde ayarlanmıştır. Ekstruder içerisine gelen karışım, sıcaklığın ve kovan içerisindeki sürtünmenin etkisi ile erimeye başlamıştır. Kafadan çıkan erimiş haldeki karışım kesilerek soğuk su banyosu içerisine konulmuş ve soğutularak sertleşmesi sağlanmıştır. Ekstruderin ucunda bulunan kafadan çıkan malzeme soğutulduktan sonra kırıcı yardımıyla küçük parçacıklar haline getirilmiştir. Elde edilen parçacıklar nemli oldukları için 12 saat süreyle $103 \pm 2{ }^{\circ} \mathrm{C}$ sıcaklıktaki etüv de bekletilmiştir. Kurutulan bu parçacıklar 88 ton kapasiteye sahip enjeksiyon kalıplama makinesinde test örnekleri haline dönüştürülmüştür. . Bu üretim esnasında $40 \mathrm{rpm}$ vida hızı, 185-200 ${ }^{\circ} \mathrm{C}$ sıcaklık kullanılmıştır. Enjeksiyon basınc1 $100 \mathrm{MPa}$ ve enjeksiyon hızı $80 \mathrm{~mm} / \mathrm{sn}$ olarak seçilmiştir.
$\mathrm{Bu}$ çalışmada üretilen polimer kompozitlerin mekanik özellikleri "Malzemelerin Test Edilmesi için kullanılan Amerikan Standartları (ASTM)"'na uygun olarak yapılmıştır. Polimerkompozitlerin mekanik özelliklerinin belirlenmesi için yapılan testler ve kullanılan standartlar aşağıdaki gibidir;

1. Eğilme direnci testi (ASTM D 790), (Anonim, 2003)

2. Çekme direnci testi (ASTM D 638), (Anonim, 2001)

3. Darbe direnci testi (ASTM D 256), (Anonim, 2000).

Eğilme direnci ve çekme direnci testleri Şekil 1'de gösterilen Zwick/Roell Z010 Universal Test Makinesi kullanılarak gerçekleştirilmiştir. Her iki mekanik özellik için 10 örnek test edilmiştir. Eğilme direnci testleri için örnekler $5 \mathrm{~mm}$ kalınlığında, $13 \mathrm{~mm}$ genişliğinde ve $165 \mathrm{~mm}$ uzunluğunda olacak şekilde kesilmiştir. Test esnasında, dayanaklar arasındaki açıklık $80 \mathrm{~mm}$ ve test hızı $2 \mathrm{~mm} /$ dak. olarak ayarlanmıştır.

Çekme direnci testleri için ise $5 \mathrm{~mm}$ kalınlığında, $13 \mathrm{~mm}$ genişliğinde ve $165 \mathrm{~mm}$ uzunluğunda örnekler kullanılmıştır. Test hızı 5 $\mathrm{mm} /$ dak. olarak ayarlanmıştır. Darbe direncini belirlemek amaciyla her grup için 10 örnek test edilmiştir. Örnekler üzerinde Şekil 2'de gösterilen Polytest RayRan cihazı yardımıyla çentik açılmıştır. Daha sonra çentikli örnekler 
Zwick/Roell HIT 5.5P (Şekil 3) makinesinde test edilmiştir.

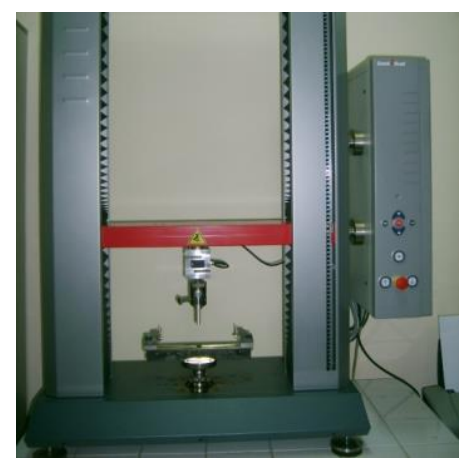

Şekil 1. Zwick/Roell Z010 Universal test makinesi.

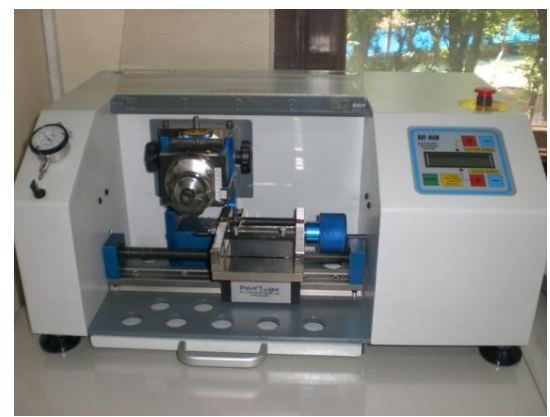

Şekil 2. Polytest RayRan çentik açma aleti.

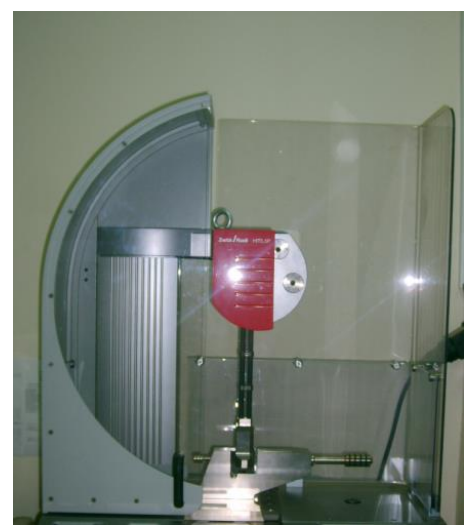

Şekil 3. Zwick/Roell HIT5.5P. Darbe testi makinesi

\section{Polimer Kompozitlerin Yoğunluklarının Belirlenmesi}

Polimer-kompozitlerin yoğunlukları (özgül ağırlık) ASTM D 792' ye uygun olarak tespit edilmiştir (Anonim, 2007). Örneklerin boyutları yaklaşık 5X20X20 mm'dir. Örneklerin ağırlıkları 0,01g duyarlılıktaki analitik terazi ile belirlenmiştir. Örneklerin sudaki ağırlıkları ise kurulu bir düzenek yardımıyla $23{ }^{\circ} \mathrm{C}$ damıtılmış suya batırıldıktan sonra belirlenmiş ve özgül ağırlıkları (ÖA) aşağıdaki eşitlik (1) yardımıyla hesaplanmıştır.

$$
\ddot{O} A=\frac{a}{[a+w)-b]}
$$

Burada;

ÖA: Özgül ağırlık

a: Örnek ağırlı̆̆ı (gr)

b: Suya batırıldıktan sonra örneğin ve batırma aparatının ağırlığı (kullanılan su dahil) (gr)

w: Batırma aparatının ağırlığı (kullanılan su dahil) (gr)

\section{Veri analizi}

$\mathrm{Bu}$ çalışmada üretilen deneme gruplarına ait veri analizleri Desing Expert ${ }^{\circledR}$ Version 7.0.3. İstatistik paket programı kullanılmıştır. Faktörlerin etkilerini belirlemek amaciyla ANOVA testi uygulanmıştır.

\section{Bulgular ve Tartışma}

YYPE ve nişasta kullanılarak üretilen polimer kompozitlerin yoğunlukları belirlenmiştir. Elde edilen sonuçlar Şekil 4' de gösterilmiştir.

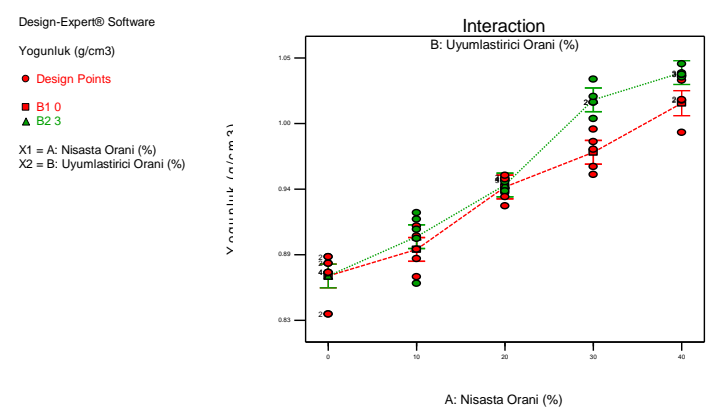

Şekil 4. Üretilen örneklerin yoğunlukları

Üretilen örneklerin yoğunluk değerleri incelendiğinde YYPE içerisine katılan nişastanın arttırılmasiyla elde edilen polimer kompozitlerin yoğunluklarının arttığı tespit edilmiştir. Uyum sağlayıcı kimyasalın eklenmesiyle benzer şekilde yoğunluğu arttırdığı belirlenmiştir. Polimer içerisindeki dolgu maddelerinin miktarı arttıkça kompozit malzemenin yoğunluklarında artış olacağı çeşitli araştırmacılar tarafından 
belirtilmiştir (Mengeloglu ve Karakus, 2012). Raj ve ark., (2001) tarafindan yapılan bir çalışmada polimer içerisindeki nişasta oranın artmasıyla yoğunluk değerlerinin arttığını belirtmişlerdir. Yoğunluk değerlerinin artmasının nedeni nişasta yoğunluğunun $(1,488$ $\mathrm{gr} / \mathrm{cm}^{3}$ ) YYPE'nin yoğunluğundan daha yüksek olmasından kaynaklandığı rapor edilmiştir (Raj ve ark., 2001). YYPE esaslı polimer kompozitlerin mekanik özelliklerinin belirlenmesi amaciyla çekme, eğilme ve darbe direnci testleri gerçekleştirilmiştir. Elde edilen sonuçlar Şekil 5.6.7'de gösterilmiştir. Çekme direnci değerleri incelendiğinde polimer kompozitler içerisindeki nişasta unu oranı arttıkça bu direncin genel olarak azaldığ gözlemlenmiştir (Şekil 5). Dolgu maddesinin miktarının artmasıyla çekme direncindeki bu azalma polimer matris ile nişasta arasındaki bağlanmanın zayıf olmasından kaynaklandığı düşünülmektedir (Mani ve Bhattacharya, 2001; $\mathrm{Wu}, 2003)$. Uyumsuzluk gideri kimyasalın etkisine bakıldığında ise YYPE esaslı polimer kompozitlerin içerisine MAPE kimyasalının daha iyi performans sağladığı belirlenmiştir. Çekme direncindeki bu azalma farklı araştırmacılar tarafindan da tespit edildiğ $i$ görülmüştür (Park ve ark., 2002; Wu, 2003). Mani ve Bhattacharya (2001) tarafindan yapilan bir çalışmada polikaprolakton (PCL), polibutilen saksinit (PBS) ve butandiol adipate tereftalat (BAT) içerisine nişasta oranının artmasıyla çekme direnci ve kopmada uzama değerlerinin azalttığını belirtmişlerdir.

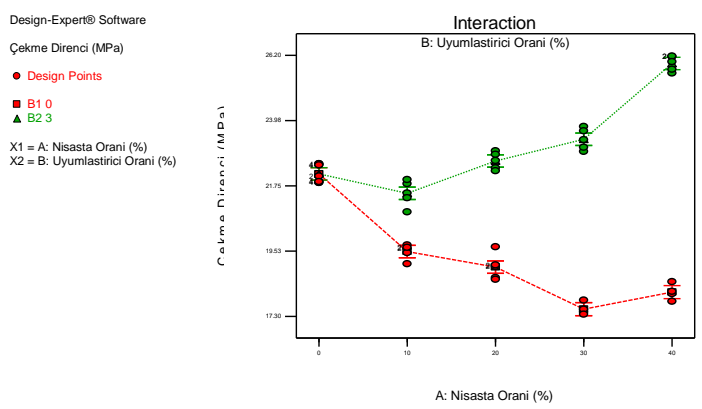

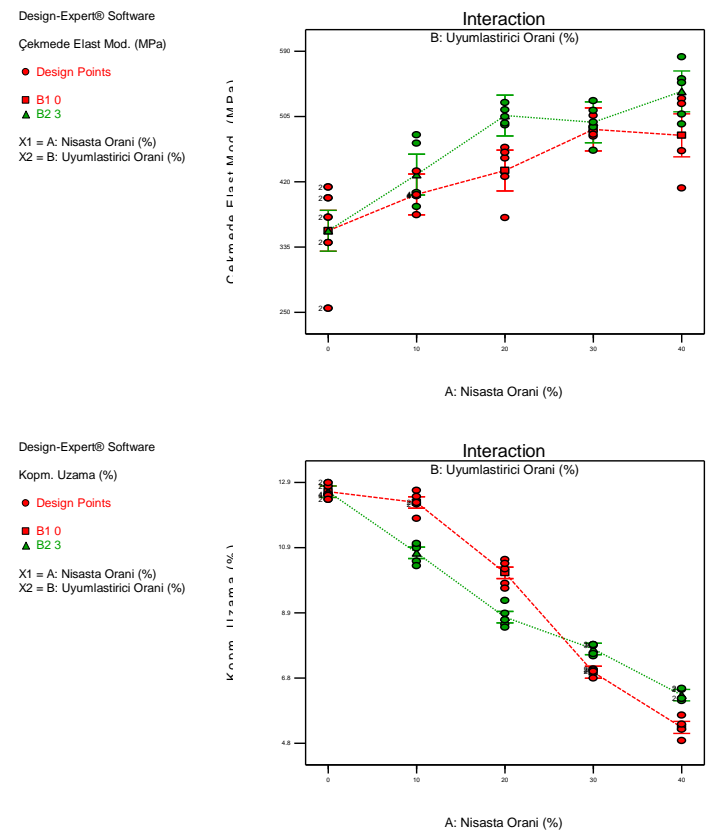

Şekil 5. Üretilen örneklerin çekme direnci değerleri

Çekmede elastikiyet modülü değerlerine bakıldığında ise dolgu maddesi miktarının etkili olduğu ve sonuçları olumlu yönde etkilediği belirlenmiştir. $\mathrm{Bu}$ durum basitçe karışım kuralıyla açıklanabilir. Organik dolgu maddelerinin plastik malzemeye kiyasla daha yüksek elastikiyet modülüne sahip olduğu ve bu iki malzemenin karıştırılması esnasında dolgu maddesi miktarı arttıkça bu değerinde artması beklendiği rapor edilmiştir (Matuana ve Balatinecz, 1998). Çekmede elastikiyet modülünde de karışım kuralına uygun olarak elastikiyet modülünün arttığ1 görülmüştür. Kompozitlerin özelliklerin belirlenmesi amaciyla yapılan çekme testi esnasında elde edilen kopmada uzama değerlerine bakıldığında (Şekil 5) dolgu maddesi miktarındaki artışa paralel olarak bu değerde azalma meydana geldiği görülmüştür. Polimer kompozit içerisine MAPE eklenmesiyle kopmada uzama değerini daha fazla azalttığ belirlenmiştir. Bu durum polimer içerisine katılan dolgu maddesi ve MAPE'nin elde edilen kompozit malzemeyi daha kırılgan hale getirdiği düşünülmektedir (Mengeloğlu ve Karakuş, 2008). Eğilme direnci özellikleri incelendiğinde dolgu maddesi miktarının etkili olduğu görülmüştür. Polimer kompozitler 
içerisindeki nişasta unu oranı arttıkça bu direncin arttığ1 görülmüştür (Şekil 6). Uyumsuzluk gideri kimyasalın etkisine bakıldığında ise YYPE esaslı polimer kompozitlerin içerisine MAPE kimyasalının eklenmesiyle eğilme direnci değerlerini daha fazla arttığı belirlenmiştir. Benzer sonuçlar farklı dolgu maddesiyle üretilen polimer kompozitlerde de tespit edilmiştir. Eğilmede elastikiyet modülü değerlerine bakıldığında (Şekil 6) ise çekmede elastikiyet modülüne benzer sonuçların elde edildiği görülmektedir. Dolgu maddesi miktarındaki artışa paralel olarak eğilmede elastikiyet modülü değerlerinde de artış olduğu görülmüştür. YYPE içerisine MAPE kimyasalının eklenmesiyle eğilme direnci değerlerini daha fazla arttığ belirlenmiştir.

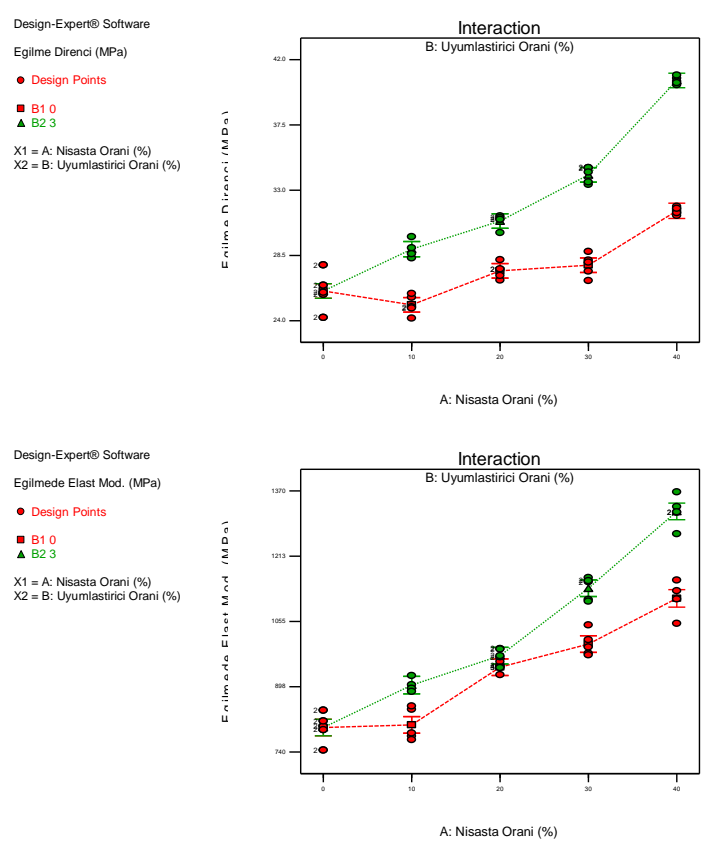

Şekil 6. Üretilen örneklerin eğilme direnci değerleri

Şekil 7' de darbe direnci değerlerine bakıldığında ise dolgu maddesi miktarının etkili olduğu gözlemlenmektedir. YYPE matrisi içerisine dolgu maddesinin girmesi kompozit malzemenin elastikiyet modülünü artırmakta, malzemeyi daha kırılgan hale getirmekte ve dolayısıyla darbe direnci değerlerini de düşürmektedir.

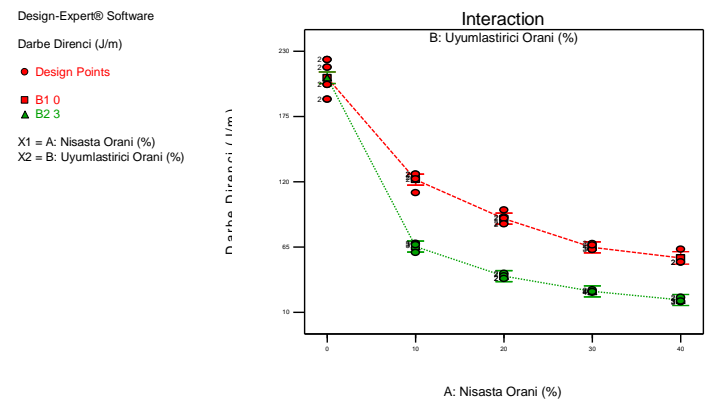

Şekil 7. Üretilen örneklerin darbe direnci değerleri

\section{Sonuç ve Öneriler}

$\mathrm{Bu}$ çalışmada mısır nişastası unu kullanılarak YYPE esaslı polimer kompozitler üretilmiştir. Üretilen polimer kompozitlerin fiziksel özellikleri (yoğunluk) ve mekanik özellikleri (çekme, eğilme ve darbe direnci) tespit edilmiştir. Elde edilen sonuçlara göre; YYPE içerisine organik dolgu maddesi olarak nişastanın eklenmesiyle polimer kompozitlerin çekme, kopmada uzama ve darbe direnci değerlerinin genel olarak azaldığı ancak çekmede elastikiyet, eğilme direnci ve eğilmede elastikiyet modülü değerlerinin arttığ1 belirlenmiştir. Nişasta oranın artmasına paralel olarak üretilen polimer kompozitlerin yoğunluk değerlerinin de arttığı tespit edilmiştir. MAPE eklenmesiyle eğilme direnci, çekme ve eğilme de elastikiyet modülü değerlerini arttığ1 görülmüştür. Polimer kompozit üretiminde uyum sağlayıcı kimyasal kullanımının polimer ve nişasta arasındaki yüzeyler arası bağlanmayı arttırmasından dolayı mekanik özellikler üzerinde olumlu etki yaptığı belirlenmiştir. Polimer kompozitlerin üretiminde organik dolgu maddesi olarak nişastanın kullanılabileceği gösterilmiştir.

\section{Kaynaklar}

Anonim 2000. Standard Test Methods for Impact Resistance of Plastics and Electrical Insulating Materials, ASTM D 256, Annual Book of American Society for Testing and Materials (ASTM) Standards, Philadelphia.

Anonim 2001. Standard Test Method for Tensile Properties of Plastics, ASTM D 638, Annual Book of American Society for Testing 
and Materials (ASTM) Standards, Philadelphia.

Anonim 2003. Standard Test Methods for Flexural Propertiesof Unreinforced and Reinforced Plastics and Electrical Insulating Materials, ASTM D 790, Annual Book of American Society for Testing and Materials (ASTM) Standards, Philadelphia.

Anonim 2007. Standard Test Method for Density and Specific Gravity (Relative Density) of Plastics by Displacement, ASTM D 792, Annual Book of American Society for Testing and Materials (ASTM) Standards, Philadelphia.

Aydemir D. 2015. Morphological and thermal properties of cellulose nanofibrils reinforced epoxy nanocomposites, Drvna Industrija, 66 (1), 35-40.

Donmez Çavdar A., Kalaycioğlu, H., Mengeloğlu, F. 2011. Tea mill waste fibers filled thermoplastic composites: The effects of plastic type and fiber loading. Journal Reinforced Plastics and Composites, 30 (10), 833-844.

Donmez Çavdar A., Mengeloğlu F., Karakuş K. 2015. Effect of boric acid and borax on mechanical, fire and thermal properties of wood flour filled high density polyethylene composites, Measurement 60, 6-12.

Franco C.R., Cyras V.P., Busalmen J.P., Ruseckaite R.A.,, Vazquez A. 2004. Degradation of polycaprolactone/starch blends and composites with sisal fibre, Polymer Degradation and Stability, 86 (1), 95-103.

Gupta A.P., Sharma M., Kumar V. 2008. Preparation and characterization of potato starch based low density polyethylene/low density polyethylene grafted maleic anhydride biodegradable polymer composite, PolymerPlastics Technology and Engineering, 47 (9), 953-959.

Karakuş K. 2008. Üniversitemizdeki polietilen ve polipropilen atıkların polimer kompozit üretiminde değerlendirilmesi, Yüksek Lisans Tezi, Kahramanmaraş Sütçü İmam Üniversitesi, Fen Bilimleri Enstitüsü, Kahramanmaraş.

Karakuş K. 2012. Nişasta esaslı biyolojik olarak bozunabilen odun polimer kompozitlerin üretimi ve mikro hücre yöntemiyle köpüklendirilmesi, Doktora Tezi, Kahramanmaraş Sütçü İmam Üniversitesi, Fen
Bilimleri Enstitüsü, Kahramanmaraş.

Kaymakcı A. 2015. Çeşitli güçlendirici dolgularla üretilen ahşap plastik nanokompozitlerin karakterizasyonu, Doktora Tezi, İ.Ü. Fen Bilimleri Enstitüsü, İstanbul.

Lu D.R., Xiao C.M., Xu S.J. 2009. Starchbased completely biodegradable polymer materials, Express Polymer Letters, 3 (6), 366375.

Mani R., Bhattacharya M. 2001. Properties of injection moulded blends of starch and modified biodegradable polyesters, European Polymer Journal, 37 (3), 515-526.

Matuana L.M., Balatinecz J.J. 1998. Effect of surface properties on the adhesion between PVC and Wood Veneer Laminates, Polym. Eng. Sci., 38 (5), 765-773.

Mengeloglu F., Karakuş K. 2008. Thermal degradation, mechanical properties and morphology of wheat straw flour filled recycled thermoplastic, Sensors, 8, 500-519.

Mengeloglu F., Karakuş $\quad$ K. 2012. Mechanical properties of injection-molded foamed wheat straw filled HDPE biocomposites: The effects of filler loading and coupling agent contents, Bioresources, 7 (3), 3293-3305.

Muthukumar T., Aravinthan A., Mukesh D. 2010. Effect of environment on the degradation of starch and pro-oxidant blended polyolefins, Polymer Degradation and Stability, 95 (10), 1988-1993.

Oakley P. 2010. Reducing the water absorption of thermoplastic starch processed by extrusion, Master of Applied Science, Department of Chemical Engineering and Applied Chemistry, University of Toronto.

Park H.M., Lee S.R., Chowdhuryy S.R., Kang T.K., Kim H.K., Park S., Ha C.S., 2002. Tensile properties, morphology, and biodegradability of blends of starch with various thermoplastics, Journal of Applied Polymer Science, 86 (11), 2907-2915.

Raj B., Annadurai V., Somashekar R., Raj M., Siddaramaiah S. 2001. Structure-property relation in low-density polyethylene-starch immiscible blends, European Polymer Journal, 37 (5), 943-948.

Tufan M., Akbas S., Gulec T., Tascioglu C., Alma M.H. 2015. Mechanical, Thermal, 
Morphological Properties and Decay Resistance of Filled Hazelnut Husk Polymer Composites, Maderas. Ciencia y tecnología 17 (4), 865 - 874.

$\mathrm{Wu}$ C.S. 2003. Physical properties and biodegradability of maleatedpolycaprolactone/starch composite, Polymer Degradation and Stability, 80 (1), 127-134. 